\title{
Sleep Microstructure Is Not Altered in Children With Attention- Deficit/Hyperactivity Disorder (ADHD)
}

\author{
I. P̌̌ÍHODOVÁ ${ }^{1}$, I. PACLT ${ }^{2}$, D. KEMLINK ${ }^{1}$, S. NEVŠÍMALOVÁ ${ }^{1}$ \\ ${ }^{1}$ Department of Neurology and Center of Clinical Neuroscience, Charles University in Prague, First \\ Faculty of Medicine and General University Hospital in Prague, Czech Republic, ${ }^{2}$ Department of \\ Psychiatry, Charles University in Prague, First Faculty of Medicine and General University \\ Hospital in Prague, Czech Republic
}

Received May 12, 2011

Accepted November 4, 2011

On-line December 20, 2011

\section{Summary}

The high rate of occurrence of sleep disturbances in children with attention-deficit/hyperactivity disorder (ADHD) prompted the idea that structural and neurotransmitter changes might give rise to specific sleep pattern abnormalities. The aim of this study was to evaluate the microstructure of sleep in children with ADHD who had no polysomnographically diagnosed sleep disorder, had never been treated for ADHD, and were free from any psychiatric comorbidity. Participants were 14 patients with ADHD (12 boys

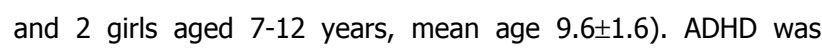
diagnosed according to DSM-IV criteria (Diagnostic and statistical manual of mental disorders). Psychiatric comorbidities were ruled out by detailed psychiatric examination. The patients underwent two consecutive overnight video-polysomnographic (PSG) recordings, with the sleep microstructure (cyclic alternating pattern - CAP) scoring during the second night. The data were compared with age- and sex-matched controls. Sleep microstructure analysis using CAP revealed no significant differences between the ADHD group and the controls in any of the parameters under study. In conclusions, no ADHD-specific alterations were found in the sleep microstructure.

\section{Key words}

Attention-deficit/hyperactivity disorder - Nocturnal videopolysomnography $\bullet$ Cyclic alternating pattern

\section{Corresponding author}

Iva Prihodova, Dpt. of Neurology, Charles University in Prague, First Faculty of Medicine and General Teaching Hospital, Katerinska 30, 12808 Praha 2, Czech Republic. E-mail: iva.prihodova@lf1.cuni.cz

\section{Introduction}

Affecting some $4-12 \%$ of children, attentiondeficit/hyperactivity disorder (ADHD) is the most frequent neurobehavioral disorder in that particular age bracket (Biederman and Faraone 2005). To go by parental data, sleep disorders in children with ADHD occur at a rate of 50-60 \% (Corkum et al. 1998, Owens et al. 2000), indeed, they used to be part of the diagnostic criteria for ADHD (American Psychiatric Association 1980). The assumption was that neurotransmitter and structural changes underlying ADHD might also underlie changes in the sleep structure and sleep disturbances (O'Brien and Gozal 2004). However, as follows from reviews and meta-analytic studies, there is no convincing proof of any consistent ADHD-specific changes in the duration of sleep or in the sleep macrostructure (Cohen-Zion and Ancoli-Israel 2004, Sadeh et al. 2006, Cortese et al. 2006, 2009). The latter, however, fails to provide complete information for rating the quality and function of sleep. In some sleep disorders (obstructive sleep apnea - OSA, periodic limb movements in sleep - PLMS) the macrostructure remains unaltered in the presence of a number of daytime manifestations arising from fragmented sleep (Bonnet et al. 1989, 2003). The microstructure is reflected in the number of arousals as it signals the degree of sleep disturbance and correlates with daytime complaints (Roehrs et al. 1989). Sleep microstructure analysis is important especially in children. Arousals and changes in sleep macrostructure are less frequent than in adults due to a higher arousal 
threshold (McNamara et al. 1996, Scholle et al. 2001, O'Brien et al. 2004). Comprehensive microstructure rating facilitates the determination of cyclic alternating pattern (CAP) events (Terzano et al. 2001) which are seen as sensitive indicators of sleep fragmentation in children (Bruni et al. 2002, Ferri et al. 2005).

The purpose of our effort was to study the microstructure of sleep by means of CAP after the inclusion of an adaptation night in a group of children with ADHD yet without any concurrent sleep disorder or psychiatric comorbidities, and never treated for ADHD before.

\section{Participants and Methods}

\section{Participants}

The cohort was made up of 14 children (12 boys and 2 girls aged 7-12 years, mean age 9.6 \pm 1.6 ), participants in a previous study (Prihodova et al. 2010), who had no sleep disorder revealed during nocturnal video-polysomnography (PSG). All were enrolled in the study before the start of medication for ADHD. The enrollment criteria were as follows: 1) ADHD diagnosed on the basis of DSM-IV (American Psychiatric Association 1994), 2) no previous pharmacological treatment for ADHD, 3) no history of any chronic physical condition (including obesity), chronic sleep disorder, neurological or other psychiatric disorders (including mental retardation and autism) based on a complete pediatric report and on neurological and psychiatric examination, 4) no current medication (psychotropic or general), 5) the patient's and his/her parents' willingness to participate in the study and informed consent signed by the parents.

The cohort underwent psychological, psychiatric and neurological testing. The diagnosis of ADHD was established by means of a detailed clinical interview which included a structured psychiatric examination - Children's Psychiatric Rating Scale (Fish 1985) and DSM-IV diagnostic criteria for ADHD (American Psychiatric Association 1994). These criteria were also used for the classification of ADHD subtypes. A combined type of ADHD was predominant (12 patients), 2 had an inattentive type of ADHD. The Conners' Parent Rating Scale (Conners 1997) was also employed to assess the severity of ADHD symptoms (a score of at least 2 SD above the mean on this scale and ADHD index were used to classify the children as having significant ADHD symptoms). To forestall any emotional and behavioral problems, the following additional tools were employed: Child Behavior
Checklist for parents, Children's Manifest Anxiety Scale and Children's Depression Inventory.

The control group was made up by 12 children ( 8 boys, 4 girls, age range $7-12$ years, mean age $9.0 \pm 1.6$ ) who had likewise participated in the previous study and in whom no sleep disorder was revealed during nocturnal PSG. They had no chronic morbidity and used no medication. The diagnosis of ADHD was ruled out according to DSM-IV criteria. The Conners' Parent Rating Scale and Child Behavior Checklist were also administered. The results of psychiatric scales are summarized in Table 1.

Table 1. Characteristics of participants: results of psychiatric scales.

\begin{tabular}{lccc}
\hline Psychiatric scale & $\begin{array}{r}\text { ADHD } \\
(\mathbf{n}=\mathbf{1 4})\end{array}$ & $\begin{array}{c}\text { Controls } \\
(\mathbf{n}=\mathbf{1 2})\end{array}$ & P value \\
\hline $\begin{array}{l}\text { CPRS Global } \\
\text { index total }\end{array}$ & $77.5 \pm 13.9$ & $45.8 \pm 4.5$ & $\mathrm{p}<0.001$ \\
ADHD index & $84.1 \pm 15.8$ & $43.2 \pm 1.8$ & $\mathrm{p}<0.001$ \\
CBCL total & $72.1 \pm 16.9$ & $45.9 \pm 8.5$ & $\mathrm{p}<0.001$ \\
\hline
\end{tabular}

T-scores are provided. Data are presented as mean \pm standard deviation. CPRS - Conners' Parent Rating Scale, ADHD attention-deficit/hyperactivity disorder, CBCL - Child Behavior Checklist

\section{Methods}

Children with ADHD and the controls had nocturnal PSG performed for 2 consecutive nights in the sleep laboratory. The first one was rated as an adaptation night. A Schwarzer polygraph was used for all PSG studies with electroencephalographic (EEG) montage (F4-C4, C4-P4, F3-C3, C3-P3, C4-A1, C3-A2), horizontal electrooculography, submental and bilateral anterior tibialis electromyography, electrocardiography and videorecording using an infrared-light camera. This type of EEG montage was used in our laboratory to allow detection of epileptiform discharges in children. Oronasal airflow was monitored with thermistors. Thoracic and abdominal respiratory movements were recorded using belts with piezosensors. Respiratory sounds were microphone-monitored. Oxyhemoglobin saturation was measured using pulse oximetry (Schwarzer EPAS 32). Neither esophageal pressure measurement nor a nasal cannula/pressure transducer were used. The nasal cannula/pressure transducer offers a more accurate method for the evaluation of subtler forms of sleep 
disordered breathing, i.e. for the detection of the upper airway resistance syndrome.

The second-night record was used for scoring. The sleep stages were visually scored according to the Rechtschaffen and Kales standard criteria in 30-second epochs (Rechtschaffen and Kales 1968). Conventional sleep parameters (total sleep time, sleep efficiency, sleeponset latency, rapid eye movement sleep latency, percentage of sleep stages, movement time) were evaluated. Apneas and hypopneas were scored to determine the apnea index (AI) and the apnea-hypopnea index (AHI) (American Thoracic Society 1996). AHI $>1$ was considered abnormal relative to normative data in children (Marcus et al. 1992). Periodic limb movements (PLM) were scored according to standard International classification of sleep disorders (ICSD-2) criteria (American Academy of Sleep Medicine 2005). The periodic limb movement index (PLMI) was calculated as the number of PLM per hour of sleep. As a cut-off for abnormality we chose PLMI $>5$, a value generally considered abnormal in children (American Academy of Sleep Medicine 2005).

Each sleep record was transformed into the EDF format, converted and rated with Somnologica TM, Flaga-Medcare, Iceland, a software which enables visual scoring of phase-A subtypes. The text file with the results was exported and processed by a software HypnoLab vers.1.2.177, SWS-Soft which automatically analyses CAP parameters.

CAP was scored following the criteria published by Terzano et al. (2001).

CAP is a periodic EEG activity during non rapid eye movement (NREM) sleep characterized by repeated spontaneous sequences of transient events (phase A), whose frequency and amplitude differ from the background activity of that sleep stage (the amplitude should be one third higher than that recorded in the preceding 2 seconds). Return to the background activity is called phase B. Each phase lasts 2 to 60 seconds. Phase $\mathrm{A}$ and $\mathrm{B}$ together form a CAP cycle. The presence of at least two CAP cycles following one another adds up to a CAP sequence. The absence in the graph of any signs of CAP for longer than 60 seconds is described as non-CAP.

Phase $\mathrm{A}$ is divided into 3 subtypes reflecting different level of the arousal during NREM sleep (Fig. 1, Fig. 2).

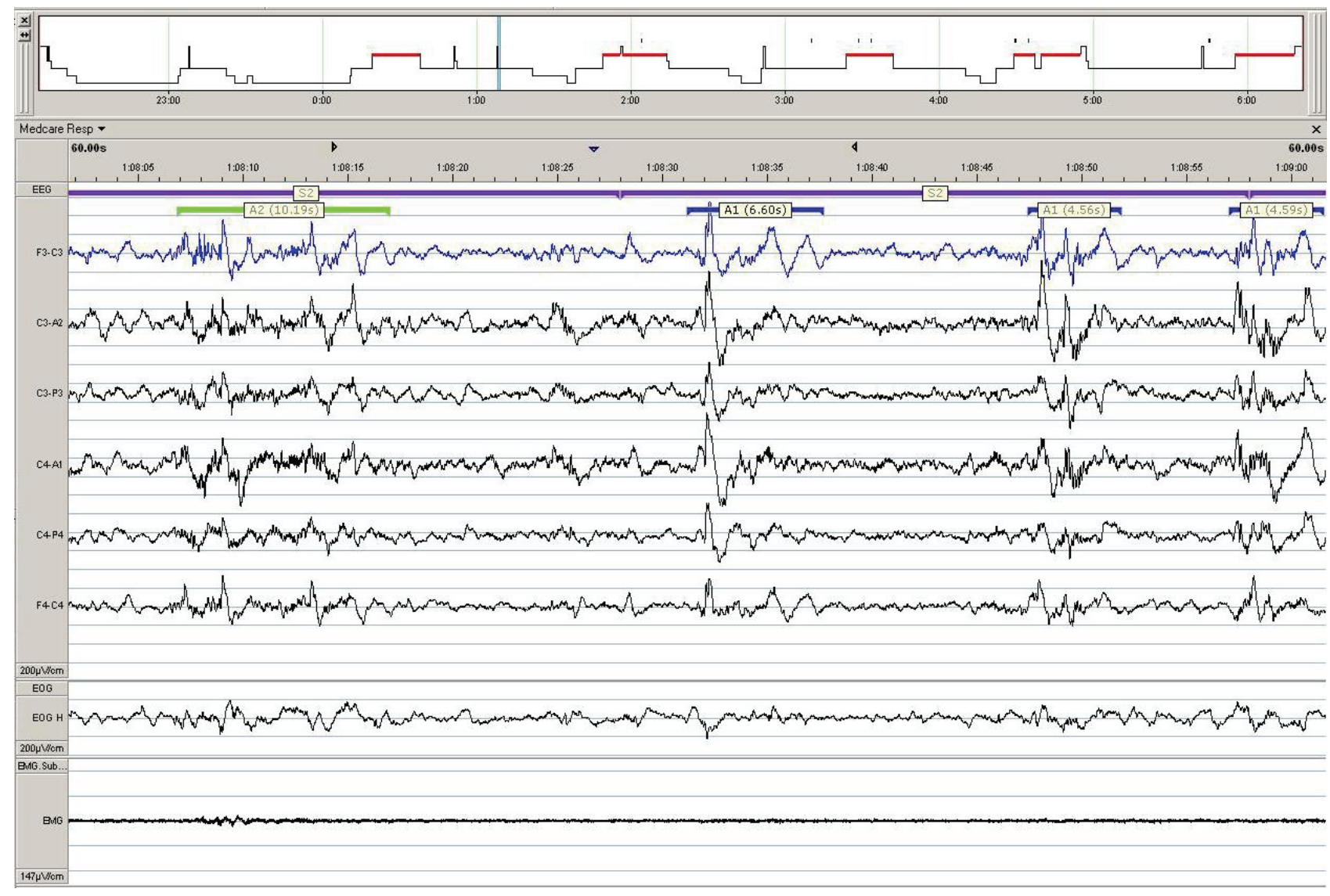

Fig. 1. CAP - examples of subtypes $A 1$ and $A 2$ (page 60 seconds). Channels are from top to bottom: EEG (electroencephalogram) leads: F3-C3, C3-A2, C3-P3, C4-A1, C4-P4, F4-C4, EOG (horizontal electrooculogram), EMG (chin electromyogram). 


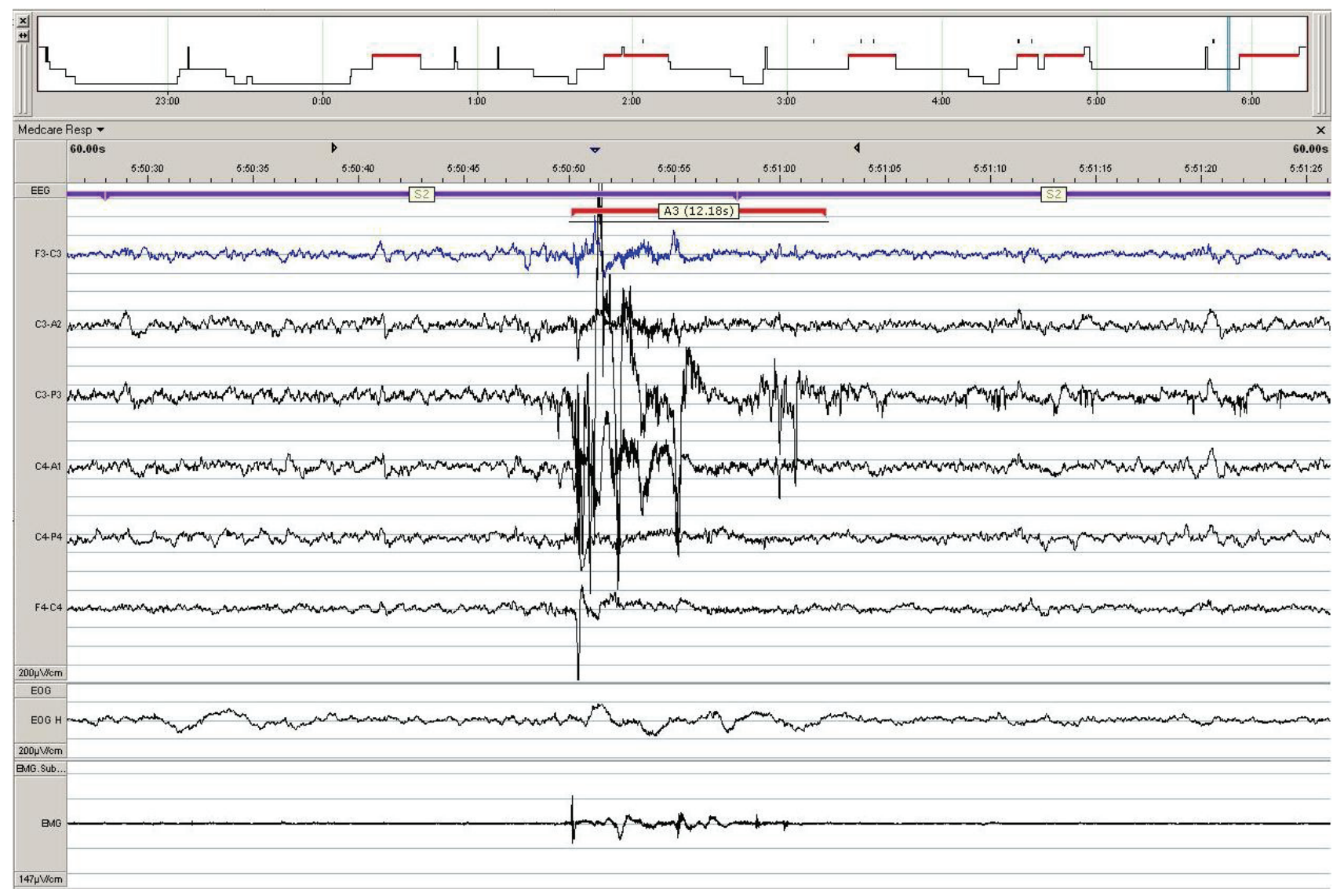

Fig. 2. CAP - example of subtype $A 3$ (page 60 seconds). Channels are from top to bottom: EEG (electroencephalogram) leads: F3-C3, C3-A2, C3-P3, C4-P4, C4-A1, F4-C4, EOG (horizontal electrooculogram), EMG (chin electromyogram).

A1 - predominantly synchronized EEG pattern (intermittent alpha rhythm in NREM 1 sleep, vertex waves, K-complex sequences, delta bursts, polyphasic bursts of slow and fast rhythms in the other sleep stages), containing less than $20 \%$ of desynchronized activity.

A2 - partially desynchronized pattern with slow high-voltage activity followed by fast low-voltage aktivity (K-complex with alpha or beta activities, polyphasic burts) associated with moderate autonomous system activation (increase of muscle tone, cardiorespiratory rate), contains $10-50 \%$ of desynchronized activity.

A3 - desynchronized pattern with remarkable autonomous system activation; more than $50 \%$ is made up of fast, low-amplitude rhythms, such as K-alpha complexes, arousals, polyphasic bursts.

The following CAP parameters were determined: CAP time (a sum of all CAP sequences), CAP rate (NREM sleep percentage formed by CAP sequences), number and duration of CAP cycles, number and duration of CAP sequences, number, duration and percentage of phase A (including subtypes), A1 index (number of A1 subtypes per hour of NREM sleep),
A2 index (number of A2 subtypes per hour of NREM), A3 index (number of A3 subtypes per hour of NREM), number and duration of phase $\mathrm{B}$.

\section{Statistics}

The two basic statistical characteristics, mean values and standard deviations, were calculated for each quantitative quality. The unpaired two-sample t-test (Student's test) was employed for testing the mean value differences between the ADHD group and the controls. Despite the fact, that minority of data (2 parameters out of CAP set, and those naturally not normally distributed AHI and PLMI) were not normally distributed (as shown by Kolmogorov-Smirnov test in controls), we preferred parametric test over non-parametric in order to allow further power analyses. Non-parametric comparisons were performed using Mann-Whitney's test. These statistical analyses were performed using STATISTICA version 10 (Statsoft, USA).

Cohen's d was calculated to demonstrate effect sizes in individual parameters using a web-based calculator (http://www.uccs.edu/ faculty/lbecker/). 
Table 2. Polysomnographic parameters.

\begin{tabular}{lcccc}
\hline Sleep parameters & $\begin{array}{c}\text { ADHD } \\
(\mathbf{n = 1 4})\end{array}$ & $\begin{array}{c}\text { Controls } \\
(\mathbf{n = 1 2})\end{array}$ & P value & Cohen's d \\
& $13.9 \pm 9.0$ & $11.5 \pm 6.3$ & $\mathrm{~ns}$ & 0.31 \\
Sleep onset latency (min) & $99.7 \pm 37.6$ & $92.9 \pm 49.9$ & $\mathrm{~ns}$ & 0.15 \\
REM sleep latency (min) & $530.4 \pm 27.1$ & $520.3 \pm 36.6$ & $\mathrm{~ns}$ & 0.31 \\
Total sleep time (min) & $95.1 \pm 2.7$ & $91.2 \pm 5.1$ & $\mathrm{~ns}$ & 0.96 \\
Sleep efficiency (\%) & $2.3 \pm 2.2$ & $3.1 \pm 2.3$ & $\mathrm{~ns}$ & 0.36 \\
Wakefulness (\%) & $2.2 \pm 2.6$ & $1.6 \pm 1.1$ & $\mathrm{~ns}$ & 0.30 \\
NREM 1 (\%) & $44.8 \pm 4.8$ & $44.3 \pm 5.3$ & $\mathrm{~ns}$ & 0.10 \\
NREM 2 (\%) & $24.5 \pm 3.7$ & $26.6 \pm 3.4$ & $\mathrm{~ns}$ & 0.57 \\
NREM 3,4 (\%) & $25.6 \pm 4.0$ & $24.0 \pm 3.3$ & $\mathrm{~ns}$ & 0.44 \\
REM (\%) & $0.5 \pm 1.0$ & $0.4 \pm 0.3$ & $\mathrm{nn}$ & 0.14 \\
Movement time (\%) & $0.7 \pm 0.4$ & $0.8 \pm 0.7$ & $\mathrm{nn}$ & 0.18 \\
AHI & $0.4 \pm 0.3$ & $0.5 \pm 0.3$ & $\mathrm{nn}$ & 0.33 \\
AI & $1.1 \pm 1.6$ & $2.0 \pm 4.0$ & 0.26 \\
PLMI & & & \\
\hline
\end{tabular}

REM - rapid eye movement, NREM - non rapid eye movement, AHI - apnea hypopnea index, AI - apnea index, PLMI - periodic limb movement index, ns - nonsignificant, nn - not normally distributed and also nonsignificant. The data are given as mean \pm standard deviation.

\section{Results}

Comparisons of the sleep macrostructure (Table 2) and microstructure (Table 3) revealed no differences between the two groups by means of both Student's and Mann-Whitney's test respectively of normality of distribution and violation of t-test assumptions. We did not find any changes in CAP rate, CAP time or CAP subtypes distribution between both investigated groups.

\section{Discussion}

Most PSG studies stop short of corroborating parental information about prolonged sleep-onset latency, recurrent nocturnal awakenings, shortened or variable sleep duration, nor have any deviations been found in the macrostructure of sleep (or else, individual studies have produced markedly heterogeneous if not contradictory results). Hence, the current endeavour to find an ADHDspecific sleep disorder is aimed at the microstructure of sleep.

The CAP rate is seen as a physiological indicator of sleep stability and as an expression of sleep quality (Terzano et al. 2000) correlating with subjective sleep quality rating - the higher the CAP rate, the worse the quality of sleep (Terzano et al. 1990). The CAP rate is increased in different sleep disorders (insomnia, PLMS,
OSA), and rises physiologically with age. The reference value in schoolchildren is $33 \%$, in the elderly up to $45 \%$ (Parrino et al. 1998). During the night, the CAP rate increases as sleep becomes deeper. The highest values are found in delta sleep with a growing share of mainly subtype A1. This subtype is coresponsible for the maintenance of deep sleep, representing the least variability in the level of arousal. It reflects the brain's successful effort to maintain NREM sleep despite potential internal and external arousal stimuli activating the reticular formation. When this effort fails, subtypes A2 or A3 appear in what is an arousal reaction. In this way, the sleep microstructure flexibility makes for a stable macrostructure (Terzano et al. 2000).

Comprehensive sleep microstructure evaluation with CAP in children with ADHD has so far appeared in only one study, the results of which support the hypothesis of impaired control of vigilance and arousal mechanisms in ADHD. Using a cohort of 20 children with a predominantly mixed type of ADHD, Miano et al. (2006) found a significant reduction of the CAP rate. Their finding pertained solely to subtype A1 which was reduced and lasted longer in superficial sleep (NREM 1 and 2). Children with ADHD also had fewer CAP sequences and shortened total sleep time. The authors speculate that chronic partial sleep deprivation in children with ADHD ultimately increases homeostatic sleep 
pressure, thus reducing the CAP rate. In their view, A1 reduction in NREM 2 sleep is an ADHD-specific finding.
Comparing those findings with narcoleptic patients, they see them as an abnormity of arousal mechanisms.

Table 3. CAP parameters.

\begin{tabular}{|c|c|c|c|c|}
\hline CAP parameters & $\begin{array}{c}\text { ADHD } \\
(n=14)\end{array}$ & $\begin{array}{c}\text { Controls } \\
(n=12)\end{array}$ & $P$ value & Cohen's d \\
\hline CAP rate NREM (\%) & $34.7 \pm 6.7$ & $33.8 \pm 5.9$ & $\mathrm{~ns}$ & 0.14 \\
\hline NREM 1 & $20.4 \pm 21.4$ & $12.2 \pm 16.1$ & $\mathrm{~ns}$ & 0.43 \\
\hline NREM 2 & $22.4 \pm 8.4$ & $25.4 \pm 7.0$ & $\mathrm{~ns}$ & 0.19 \\
\hline NREM 3/4 & $47.3 \pm 11.7$ & $40.1 \pm 10.4$ & ns & 0.31 \\
\hline CAP time (min) & $135.0 \pm 29.4$ & $131.1 \pm 28.9$ & $\mathrm{~ns}$ & 0.07 \\
\hline Number of CAP cycles & $394.0 \pm 61.5$ & $378.6 \pm 73.5$ & ns & 0.11 \\
\hline$A 1(\%)$ & $78.2 \pm 5.0$ & $79.4 \pm 3.6$ & ns & 0.14 \\
\hline$A 2(\%)$ & $15.1 \pm 5.0$ & $14.6 \pm 2.7$ & $\mathrm{~ns}$ & 0.06 \\
\hline$A 3(\%)$ & $6.7 \pm 2.9$ & $6.0 \pm 2.1$ & ns & 0.14 \\
\hline Al index $($ no/h) & $40.0 \pm 7.0$ & $39.2 \pm 9.1$ & ns & 0.16 \\
\hline NREM 1 & $8.2 \pm 11.0$ & $5.1 \pm 4.2$ & ns & 0.37 \\
\hline NREM 2 & $28.0 \pm 8.7$ & $32.0 \pm 9.2$ & $\mathrm{~ns}$ & 0.47 \\
\hline NREM $3 / 4$ & $68.1 \pm 16.2$ & $58.7 \pm 15.3$ & $\mathrm{~ns}$ & 0.60 \\
\hline$A 2$ index $($ no/h) & $7.5 \pm 3.2$ & $6.9 \pm 1.8$ & $\mathrm{~ns}$ & 0.15 \\
\hline NREM 1 & $4.7 \pm 10.8$ & $4.3 \pm 6.5$ & $\mathrm{~ns}$ & 0.05 \\
\hline NREM 2 & $11.8 \pm 4.6$ & $11.5 \pm 2.5$ & ns & 0.08 \\
\hline NREM 3/4 & $4.9 \pm 1.8$ & $3.7 \pm 2.0$ & ns & 0.63 \\
\hline$A 3$ index $(n o / h)$ & $2.9 \pm 1.6$ & $2.2 \pm 1.0$ & ns & 0.52 \\
\hline NREM 1 & $24.3 \pm 18.9$ & $15.6 \pm 16.4$ & ns & 0.49 \\
\hline NREM 2 & $5.0 \pm 2.3$ & $4.4 \pm 1.2$ & ns & 0.33 \\
\hline NREM $3 / 4$ & $0.7 \pm 0.7$ & $0.7 \pm 0.7$ & $\mathrm{~ns}$ & 0 \\
\hline A mean duration (sec) & $6.9 \pm 0.7$ & $7.9 \pm 1.9$ & ns & 0.70 \\
\hline A1 mean duration (sec) & $5.2 \pm 0.6$ & $5.8 \pm 1.3$ & $\mathrm{~ns}$ & 0.59 \\
\hline NREM 1 & $1.7 \pm 2.6$ & $1.6 \pm 3.3$ & $\mathrm{nn}$ & 0.03 \\
\hline NREM 2 & $5.0 \pm 0.7$ & $5.6 \pm 1.2$ & ns & 0.61 \\
\hline NREM $3 / 4$ & $5.4 \pm 0.8$ & $6.3 \pm 1.6$ & $\mathrm{~ns}$ & 0.71 \\
\hline A2 mean duration (sec) & $11.7 \pm 2.0$ & $14.2 \pm 5.1$ & ns & 0.67 \\
\hline NREM 1 & $3.5 \pm 6.0$ & $7.6 \pm 12.1$ & $\mathrm{~ns}$ & 0.42 \\
\hline NREM 2 & $10.3 \pm 1.5$ & $12.9 \pm 3.9$ & ns & 1.10 \\
\hline NREM $3 / 4$ & $18.1 \pm 5.5$ & $20.6 \pm 10.0$ & $\mathrm{~ns}$ & 0.31 \\
\hline A3 mean duration (sec) & $16.4 \pm 2.9$ & $20.8 \pm 6.8$ & ns & 0.84 \\
\hline NREM 1 & $8.1 \pm 5.4$ & $9.7 \pm 7.0$ & $\mathrm{~ns}$ & 0.26 \\
\hline NREM 2 & $16.6 \pm 2.9$ & $20.5 \pm 6.0$ & ns & 0.83 \\
\hline NREM $3 / 4$ & $19.6 \pm 14.2$ & $23.2 \pm 22.8$ & ns & 0.19 \\
\hline B mean duration (sec) & $22.1 \pm 1.5$ & $22.1 \pm 4.1$ & ns & 0 \\
\hline Cycle mean duration (sec) & $28.8 \pm 1.7$ & $29.8 \pm 3.1$ & ns & 0.36 \\
\hline CAP sequences (no) & $40.2 \pm 4.7$ & $38.9 \pm 7.2$ & ns & 0.20 \\
\hline Sequence mean duration (sec) & $204.3 \pm 35.1$ & $206.8 \pm 27.0$ & ns & 0.08 \\
\hline Number of cycles in sequence & $8.1 \pm 1.2$ & $8.0 \pm 1.4$ & $\mathrm{~ns}$ & 0.08 \\
\hline
\end{tabular}

The data are given as mean \pm standard deviation. CAP - cyclic alternating pattern, NREM - non rapid eye movement, $\mathrm{ns}$ - nonsignificant, nn - not normally distributed and also nonsignificant 
In our study of children with ADHD we found no significant differences in any of the CAP parameters. As for the microstructure of sleep, we could not corroborate the hypothesis of chronic sleep deprivation in children with ADHD or of a disorder of arousal mechanisms.

The cause of this discrepancy between our own and the Miano et al. (2006) study is unclear. The interpretation of a lower occurrence of subtype A1 in superficial sleep is not quite consistent, because already in delta sleep the share of A1 was within norm. Nor is it clear why a change in the stability of sleep should selectively comprise NREM $1 / 2$ phases and not also synchronous sleep with its predominance of the A1 phase. Indeed, a recent study by Silvestri et al. (2009) carries evidence of an increased number of arousals in children with ADHD who, relative to CAP scoring, have an equivalent in subtypes $\mathrm{A} 2$ and $\mathrm{A} 3$.

The differences in the outcome of our study may also lie in the variability of CAP scoring. Unlike the scoring of the macrostructure of sleep where congruence is very likely, the scoring of sleep microstructure parameters (arousals) may differ from centre to centre (Bonnet et al. 2007). Evidence of this inter-centre variability can be read from works by Bruni et al. (2002) and Lopes et al. (2005), who studied CAP in healthy, age-matched children and who arrived at markedly different results. Bruni et al. (2002), found a CAP rate of $33 \%$ in a group aged 6-10 years, while Lopes et al.
(2005), calculated a rate of $65 \%$ in a cohort of children aged $8-12$ years.

Even though Ferri et al. (2005) revealed intercentre agreement in the scoring of the basic parameters of CAP, in a detailed analysis (shares of different subtypes in sleep stages and their duration) this agreement was already less expressed. Another potential limitation of our study may represent the relatively small sample size.

\section{Conclusion}

Having studied previously untreated children free from psychiatric comorbidities and sleep disorders, we found no specific changes in their sleep microstructure. Our findings do not support the theory of chronic sleep deprivation in children with ADHD or of impaired control of vigilance and arousal mechanisms. This discrepance between our findings and the only present-day study of that particular aspect calls for more research using larger cohorts to verify the results.

\section{Conflict of Interest}

There is no conflict of interest.

\section{Acknowledgements}

The study was supported by the Czech Ministry of Education (research program MSM 0021620849) and by the Czech Ministry of Health (research grant NR 95343/2007, grant IGA MZ CR NT 12141-3/2010).

\section{References}

AMERICAN PSYCHIATRIC ASSOCIATION: Diagnostic and Statistical Manual of Mental Disorders. $3^{\text {rd }}$ ed., American Psychiatric Association, Washington, 1980.

AMERICAN PSYCHIATRIC ASSOCIATION: Diagnostic and Statistical Manual of Mental Disorders. $4^{\text {th }}$ ed., American Psychiatric Association, Washington, 1994.

AMERICAN THORACIC SOCIETY: Standards and indications for cardiopulmonary sleep studies in children. Am $J$ Respir Crit Care Med 153: 866-878, 1996.

AMERICAN ACADEMY OF SLEEP MEDICINE: The International Classification of Sleep Disorders. Diagnostic and Coding Manual. $2^{\text {nd }}$ ed., Westchester, IL, 2005.

BIEDERMAN J, FARAONE S: Attention-deficit hyperactivity disorder. Lancet 366: 237-248, 2005.

BONNET MH: Infrequent periodic sleep disruption: effects on sleep, performance and mood. Physiol Behav 45: 10491055, 1989.

BONNET MH, ARAND D: Clinical effects of sleep fragmentation versus sleep deprivation. Sleep Med Rev 7: 297-310, 2003.

BONNET MH, DOGHRAMJI K, ROEHRS T, STEPANSKI EJ, SHELDON SH, WALTERS AS, WISE M, CHESSON AL Jr: The scoring of arousal in sleep: reliability, validity, and alternatives. J Clin Sleep Med 3: 133-145, 2007. 
BRUNI O, FERRI R, MIANO S, VERRILLO E, VITTORI E, DELLA MARCA G, FARINA B, MENNUNI G: Sleep cyclic alternating pattern in normal school-age children. Clin Neurophysiol 113: 1806-1814, 2002.

COHEN-ZION M, ANCOLI-ISRAEL S: Sleep in children with attention-deficit hyperactivity disorder (ADHD): a review of naturalistic and stimulant intervention studies. Sleep Med Rev 8: 379-402, 2004.

CONNERS CK: Conners' Rating Scales - Revised. Multi-Health Systems Publishing, North Tonowanda, NY, 1997.

CORKUM P, TANNOCK R, MOLDOFSKY H: Sleep disturbances in children with attention-deficit/hyperactivity disorder. J Am Acad Child Adolesc Psychiatry 37: 637-646, 1998.

CORTESE S, KONOFAL E, YATEMAN N, MOUREN M, LECENDREUX M: Sleep and allertness in children with attention-deficit/hyperactivity disorder: a systematic review of the literature. Sleep 29: 504-511, 2006.

CORTESE S, FARAONE SV, KONOFAL E, LECENDREUX M. Sleep in children with attention-deficit/hyperactivity disorder: meta-analysis of subjective and objective studies. J Am Acad Child Adolesc Psychiatry 48: 894-908, 2009.

FERRI R, BRUNI O, MIANO S, SMERIERI A, SPRUYT K, TERZANO MG: Inter-rater reliability of sleep cyclic alternating pattern (CAP) scoring and validation of a new computer-assisted CAP scoring method. Clin Neurophysiol 116: 696-707, 2005.

LOPES MC, ROSA A, ROIZENBLATT S, GUILLEMINAULT C, PASSARELLI C, TUFIK S, POYARES D: Cyclic alternating pattern in peripubertal children. Sleep 28: 215-219, 2005.

MIANO S, DONFRANCESCO R, BRUNI O, FERRI R, GALIFFA S, PAGANI J, MONTEMITRO E, KHEIRANDISH L, GOZAL D, PIA VILLA M: NREM sleep instability is reduced in children with attentiondeficit/hyperactivity disorder. Sleep 29: 797-803, 2006.

MCNAMARA F, ISSA FG, SULLIVAN CE: Arousal pattern following central and obstructive breathing abnormalities in infants and children. $J$ Appl Physiol 81:2651-2657, 1996.

O'BRIEN LM, GOZAL D: Sleep in children with attention deficit/hyperactivity disorder. Minerva Pediatr 56: 585-601, 2004.

O'BRIEN LM, TAUMAN R, GOZAL D: Sleep pressure correlates of cognitive and behavioral morbidity in snoring children. Sleep 27: 279-282, 2004.

OWENS J, MAXIM R, NOBILE C, MCGUINN M, MSALL M: Parental and self-report of sleep in children with attention deficit/hyperactivity disorder. Arch Pediatr Adolesc Med 154: 549-555, 2000.

PARRINO L, BOSELLI M, SPAGGIARI MC, SMERIERI A, TERZANO MG: Cyclic alternating pattern (CAP) in normal sleep: polysomnographic parameters in different age groups. Electroenceph Clin Neurophysiol 107: 439-450, 1998.

PRIHODOVA I, PACLT I, KEMLINK D, SKIBOVA J, PTACEK R, NEVSIMALOVA S: Sleep disorders and daytime sleepiness in children with attention-deficit/hyperactivity disorder: a two-night polysomnographic study with a multiple sleep latency test. Sleep Med 11: 922-928, 2010.

RECHTSCHAFFEN A, KALES A: A Manual of Standardised Terminology, Techniques and Scoring System for Sleep Stages of Human Subjects. National Institute of Health, Government Printing Office; Washington DC, 1968.

ROEHRS T, ZORICK F, WITTING R, CONWAY W, ROTH T: Predictors of objective level of daytime sleepiness in patients with sleep-related breathing disorders. Chest 95: 1202-1206, 1989.

SADEH A, PERGAMIN L, BAR-HAIM Y: Sleep in children with attention-deficit hyperactivity disorder: a metaanalysis of polysomnographic studies. Sleep Med Rev 10: 381-398, 2006.

SCHOLLE S, ZWACKA G: Arousals and obstructive sleep apnea syndrome in children. Clin Neurophysiol 112: 984991, 2001.

SILVESTRI R, GAGLIANO A, ARICÓ I, CALARESE T, CEDRO C, BRUNI O, CONDURSO R, GERMANÓ E, GERVASI G, SIRACUSANO R, VITA G, BRAMANTI P: Sleep disorders in children with AttentionDeficit/Hyperactivity Disorder (ADHD) recorded overnight by video-polysomnography. Sleep Med 10:11321138, 2009.

TERZANO MG, PARRINO L, SMERIERI A, CHERVIN R, CHOKROVERTY S, GUILLEMINAULT C, HIRSHKOWITZ M, MAHOWALD M, MOLDOFSKY H, ROSA A, THOMAS R, WALTER A: Atlas, rules, and recording techniques for the scoring of cyclic alternating pattern (CAP) in human sleep. Sleep Med 2: 537$553,2001$. 
TERZANO MG, PARRINO L: Origin and significance of the cyclic alternating pattern (CAP). Sleep Med Rev 4: 101$123,2000$.

TERZANO MG, PARRINO L, FIORITI G, OROFIAMMA B, DEPOORTERE H: Modifications of sleep structure induced by increasing levels of acoustic perturbation in normal subjects. Electroencephalogr Clin Neurophysiol 76: 29-38, 1990. 